\title{
Atorvastatin-Medicated Dentifrice Significantly Inhibits CD4+ T Cell Proliferation: In vitro Pilot Study
}

\author{
Pasta Dental Medicada con Atorvastatina Inhibe de Forma Significativa \\ la Proliferación de Células T CD4+: Un Estudio Piloto In vitro
}

David R. Rosenberg'; Jeremy R. Kernitsky²; Catherine X. Andrade ${ }^{3}$; Valeria Ramirez ${ }^{3}$; Deborah Violant ${ }^{4}$ \& José Nart ${ }^{4}$

ROSENBERG, D. R.; KERNITSKY, J. R.; ANDRADE, C. X.; RAMIREZ, V. ; VIOLANT, D. \& NART, J. Atorvastatin-medicated dentifrice significantly inhibits CD4+ T cell proliferation: in vitro pilot study. Int. J. Morphol., 35(2):394-402, 2017.

SUMMARY: Reports indicate that statins (cholesterol-lowering drugs), in addition to lowering cholesterol, have an immunomodulatory effect. This effect may be beneficial for the treatment of several diseases, including periodontal disease. The aim of the present study was to evaluate the immunomodulatory effect of an atorvastatin-medicated dentifrice on CD4+ T cell proliferation. CD4+ T cell proliferation assays and peripheral blood mononuclear cell (PBMC) viability assays were conducted on PBMCs from healthy donors cultured under the following conditions: control, atorvastatin solution, atorvastatin-medicated dentifrice, and dentifrice without atorvastatin at concentrations of 1, 5, 10, 50 and $100 \mu \mathrm{M}$. A Generalized Equation Estimation (GEE) model was used to analyze concentration versus proliferation and concentration versus percentage of dead cells within each group evaluated. Atorvastatin-medicated dentifrice ( $\mathrm{p}$-value $<0.0001$ ) and atorvastatin solution ( $\mathrm{p}$-value <0.0001) significantly inhibited CD4+ T cell proliferation in a dosedependent manner compared with the dentifrice without atorvastatin and control conditions. Only the relationship between atorvastatin solution and percentage of dead cells was significant compared to the other conditions ( $p$-value 0.019). The results revealed that atorvastatinmedicated dentifrice at concentrations of 1 to $100 \mu \mathrm{M}$ had immunomodulatory effects, inhibiting CD4+ T cell proliferation without affecting PBMC viability. The other components of the dentifrice did not affect CD4+ T cell proliferation or cell viability, indicating its utility as a vehicle to achieve the desired effects of atorvastatin in periodontal tissue. Controlled clinical trials are still needed to evaluate the clinical effects of an atorvastatin-medicated dentifrice on the periodontium.

KEY WORDS: Atorvastatin calcium; Dentifrices; T cells; Flow cytometry.

\section{INTRODUCTION}

The current evidence regarding the pathogenesis of periodontal disease suggests that the immune response plays a significant role in disease development and progression ( Ebersole et al., 2013; Cekici et al., 2014). The dysregulation of inflammatory and immune mechanisms in susceptible patients in response to bacterial challenge promotes the development of chronic inflammation and the destruction of periodontal tissues, thereby establishing the disease (Cekici et al.).

Entry of periodontopathogenic bacteria and their products in host tissues results in the activation of a variety of innate and adaptive immune cells and the release of different intercellular messengers. T cells are important components of the inflammatory cell infiltrate present in periodontal lesions. These cells are able to produce a number of inflammatory cytokines in response to bacterial invasion; one example of these cytokines is interferon gamma (IFN- $\gamma$ ), which can activate macrophages, which in turn release mediators associated with bone destruction, such as the receptor activator of nuclear factor kb ligand (RANKL) (Cekici et al.).

New scientific evidence of the periodontal immune response has allowed for the key regulatory role of $\mathrm{T}$ cells to be distinguished. Depending on the response type of these cells through their different phenotypes, the effect could be either protective or destructive (Gemmell et al., 2007; Okui et al., 2014).

\footnotetext{
${ }^{1}$ Department of Oral and Maxillofacial Surgery, School of Dentistry, Universidad de los Andes, Santiago, Chile.

${ }^{2}$ Department of Periodontology, School of Dentistry, Universidad de los Andes, Santiago, Chile.

${ }^{3}$ Epidemiology, School of Dentistry, Universidad de los Andes, Santiago, Chile.

${ }^{4}$ Department of Periodontology, Universitat Internacional de Catalunya, Barcelona, Spain.

This work was supported by grants from the Universidad de los Andes, Santiago de Chile, Chile: FAI-MED- IN0GTO201459
} 
The current therapeutic approaches used to manage periodontal disease are primarily aimed at controlling the etiologic agent (biofilm) and new treatment approaches regulating the immune response need to be developed.

Within this context, statins (drugs used to treat dyslipidemia) have demonstrated a number of beneficial effects against periodontal disease because of the additional properties they possess that are independent of their capacity to lower serum cholesterol (Wang et al., 2008). These additional properties are observed because, in addition to inhibiting the enzyme hydroxymethylglutaryl CoA (HMG CoA) reductase, which is responsible for cholesterol formation, statins also inhibit intermediate products, such as isoprenoids, which play a fundamental role in regulating certain proteins that control multiple cell functions (Wang et al.). Some of these effects are the improving of endothelial dysfunction, increasing the stability of atheroma plaques, decreasing oxidative stress and inflammation, inhibiting the thrombogenic response, and immunomodulation (Wang et al.).

Among their effects related to the immune response, statins can alter the morphology and motility of leukocytes, endo- and exocytic vesicle transport, phagocytosis and lysis of microorganisms, antigen processing and presentation, lymphocyte activation and proliferation, and secretion of multiple chemokines and cytokines (Lee et al., 2008). Other reports have indicated that statins may inhibit major histocompatibility complex class II (MHC II) proteins, which are essential for antigen presentation and $\mathrm{T}$ cell activation (Lee et al.; Kwak et al., 2000). They may also modify the actin in the cytoskeleton of antigen-presenting cells, altering antigen endocytosis and, thus, affecting T cell activation and proliferation (Greenwood et al., 2006).

Furthermore, statins are also able to disrupting the integrity of lipid rafts on the cell membrane, which are important microdomains that ensure the coupling of cell signaling complexes and, thus, can affect the activation of the immune response (Greenwood et al.). Additionally, statins may affect the differentiation of different $\mathrm{T}$ cell subsets, promoting a $\mathrm{T}$ helper 2 (Th2) response instead of a T helper 1 (Th1) response, thereby decreasing the levels of pro-inflammatory cytokines important for resolving bacterial infections (Greenwood et al.).

Several studies have reported improvements in clinical status, such as probing depth or the clinical attachment level of patients with periodontal disease, along with molecular changes in certain inflammatory markers, such as interleukin 6 (IL-6), due to the systemic use or topical application of statins (Lindy et al., 2008; Pradeep et al., 2010; Pradeep et al., 2013).
Considering that the immunomodulatory properties of statins may benefit patients with periodontal disease, it could be interesting to assess the immunomodulatory effects of statins using a dentifrice as a delivery vehicle, which is widely used as an adjunct in oral hygiene but has not currently been investigated as a vehicle for statin treatment.

The aim of this in vitro study was to evaluate the effects of an atorvastatin-medicated dentifrice on $\mathrm{T}$ cell viability and proliferation.

\section{MATERIAL AND METHOD}

This pilot study was conducted in accordance with the ethical considerations of the Declaration of Helsinki (64 ${ }^{\text {th }}$ General Assembly, Fortaleza, Brazil, October, 2008) and obtained the approval of the ethics committee of the School of Medicine at the University of the Andes, Santiago, Chile. Additionally, the participants ( 3 blood donors) signed an informed consent form before participating in the study.

Preparation of atorvastatin samples. The experimental samples were prepared in a laboratory of a Chilean pharmacy chain (SALCOBRAND S.A) and included the following: A solution of pure atorvastatin $(5 \mathrm{mg} / \mathrm{ml})$, atorvastatinmedicated dentifrice $(3.7 \% \mathrm{p} / \mathrm{p})$, and dentifrice without atorvastatin. The dentifrice base used was composed of menthol (5 mg), sodium fluoride (5 mg), Lutrol gel (250 $\mathrm{mg})$, and base gel ( $5 \mathrm{~g})$.

Collection and preparation of peripheral blood mononuclear cells (PBMCs). PBMCs were isolated from heparinized human peripheral blood samples $(30 \mathrm{ml})$ from 3 healthy donors using Ficoll Plus ${ }^{\mathrm{TM}}$ (Amersham Biosciences, USA). Briefly, $7 \mathrm{ml}$ of peripheral blood was added to $5 \mathrm{ml}$ of Ficoll Plus ${ }^{\mathrm{TM}}$. Then, the sample was centrifuged at $1700 \mathrm{rpm}$ for 20 minutes at room temperature. A whitish intermediate phase composed of PBMCs was collected. Next, the cells were washed with $50 \mathrm{ml}$ of PBS, centrifuged at $1800 \mathrm{rpm}$ for 10 minutes, and re-suspended in complete RPMI 1640 medium (10\% fetal bovine serum [FBS], $2 \mathrm{mM} \mathrm{L-glutamine,} 100 \mathrm{U} / \mathrm{mL}$ penicillin, and 100 $\mathrm{mg} / \mathrm{mL}$ streptomycin).

T cell proliferation assay. PBMCs were stained with Cell Trace $^{\mathrm{TM}}$ Violet probe (CTV) (\# C34557, Molecular Probes, Massachusetts, USA) following the manufacturer's instructions to assess cell proliferation assay by flow cytometry. PBMCs were cultured in complete RPMI 1640 medium and stimulated with phytohemagglutinin (PHA; 25 $\mu \mathrm{g} / \mathrm{ml})$. In addition, PBMCs were treated with: atorvastatin 
solution, atorvastatin-medicated dentifrice at different concentrations $(1,5,10,50$ and $100 \mu \mathrm{M})$, and equivalent amounts of dentifrice without atorvastatin at different concentrations or only medium for 4 days at $37{ }^{\circ} \mathrm{C}$ and 5 $\% \mathrm{CO}_{2}$. Finally, the cells were harvested and stained with anti-CD4 antibody conjugated to fluorescein isothiocyanate (FITC). Samples were analyzed on a FACS Canto II flow cytometer (Becton Dickinson), and the percentage of CD4+ T cell proliferation was analyzed using FCS Express 4 Plus Research Edition software (De Novo Software, Los Angeles, CA).

Cell viability assay. PBMCs cultures stimulated with PHA ( $25 \mathrm{mg} / \mathrm{ml})$ and exposed to different atorvastatin concentrations as described above were used to assess cell viability. Cells were stained with $1 \mathrm{mg} / \mathrm{ml}$ propidium iodide (PI) and analyzed by flow cytometry as previously described to obtain the percentage of dead cells for each condition.

Statistical analysis. The data obtained for the variables of $\mathrm{CD} 4+\mathrm{T}$ cell proliferation and cell viability were described using medians and interquartile ranges according to each exposure regimen. A Generalized Equation
Estimation (GEE) model was used for the analyses between concentration and proliferation and between the concentration and percentage of dead cells within each group, considering that the observations were not independent; the slope with its p-value is reported. A difference was considered significant with a $p$-value $<0.05$. For the evaluation of the slopes between exposition groups, the interaction between group and concentration was explored, generating a model and evaluating the p-value of this interaction. The statistical analysis was performed using Stata 12.1 software (StataCorp, Texas, USA).

\section{RESULTS}

Atorvastatin-medicated dentifrice inhibits CD4+ T cell proliferation. To evaluate the effect of an atorvastatinmedicated dentifrice on CD4+ T cell proliferation, PBMCs obtained from healthy donors were stained with CTV fluorescent dye and stimulated with PHA for 4 days. Images of the different PBMC cultures did not show evidence of a toxic effect; cells had a rounded and bright morphology under a light inverted microscope (Fig. 1).
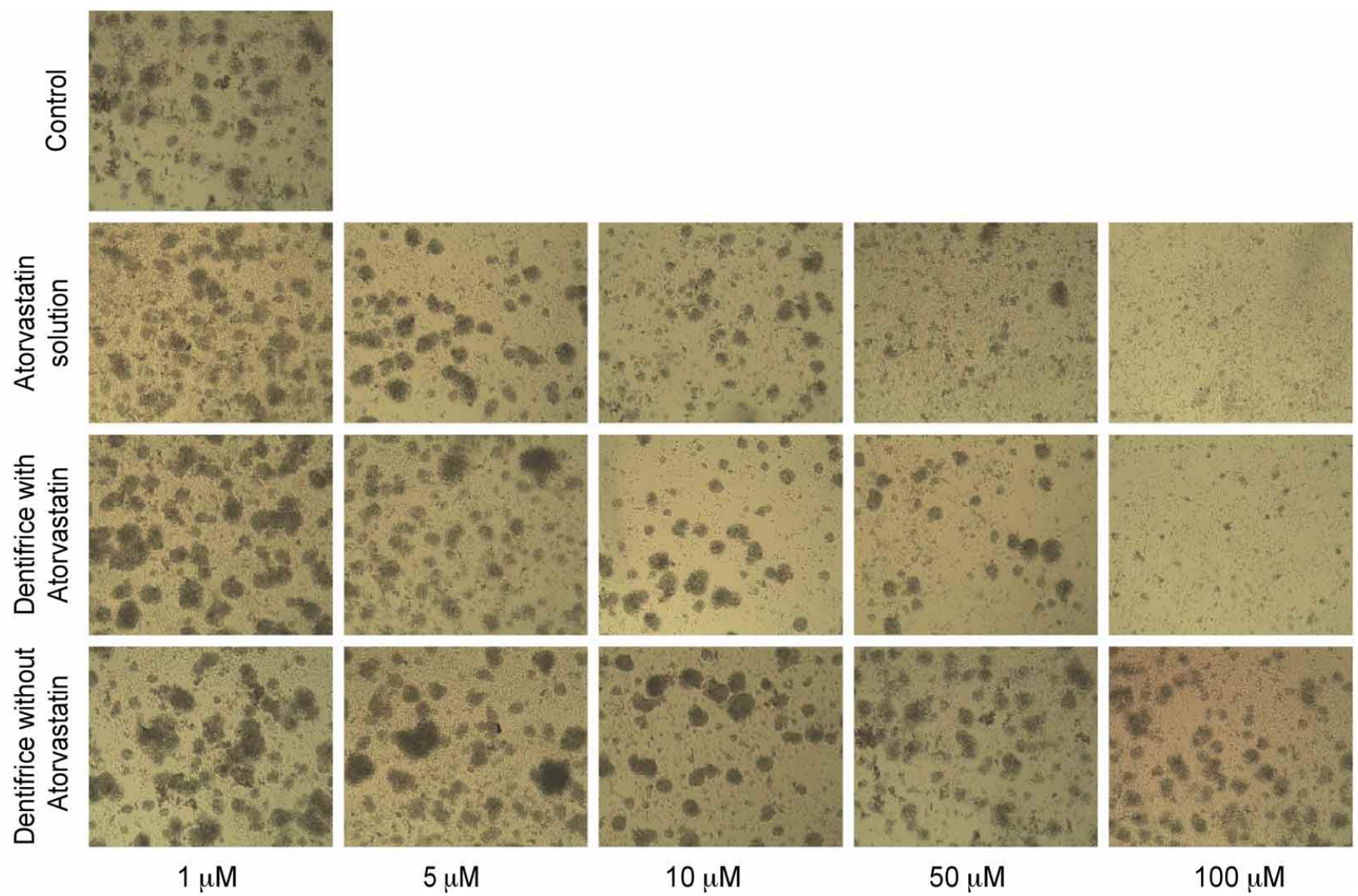

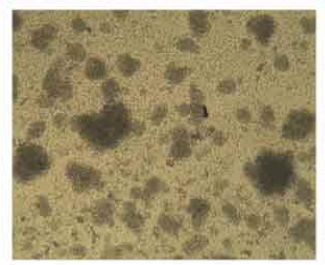

$5 \mu \mathrm{M}$

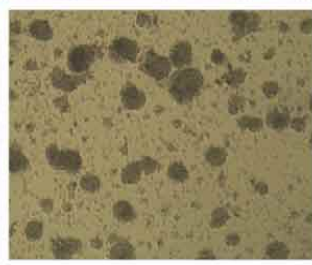

$10 \mu \mathrm{M}$

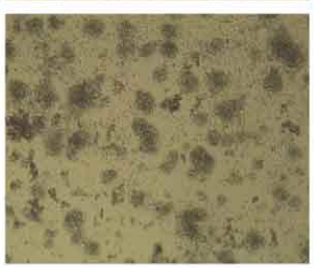

$50 \mu \mathrm{M}$

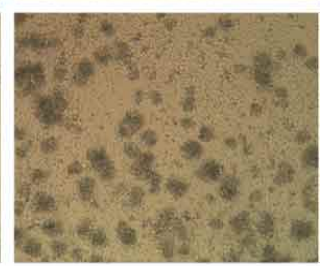

$100 \mu \mathrm{M}$

Fig. 1. Photographs of PBMC cultures at 4 days stimulated by PHA and under the different conditions assessed. 
Flow cytometry was used to analyze the CD4+ T cell proliferation rates under each condition. Figure 2 shows CD4+ T cells (gate 2) and the proliferation that occurred as CTV dye was diluted (gate 3) on samples not stimulated or stimulated with PHA (25 g $\mu \mathrm{g} / \mathrm{ml})$ after 4 days (Fig. 2).

Analysis of the proliferation assays shows that both atorvastatin solution and atorvastatin-medicated dentifrice reduced the percentage of $\mathrm{CD} 4+\mathrm{T}$ cell proliferation compared with control and dentifrice without atorvastatin.
Furthermore, the percentage of CD4+ T cells decreased as the concentrations of the atorvastatin-medicated dentifrice and atorvastatin solution increased (Fig. 3). Conversely, the percentage of CD4+ T cells remained similar at the different concentrations of dentifrice with atorvastatin, and these values were very similar to those observed in the control group (Fig. 4).

We used a Generalized Equation Estimation (GEE) model for the analysis between concentration and
A

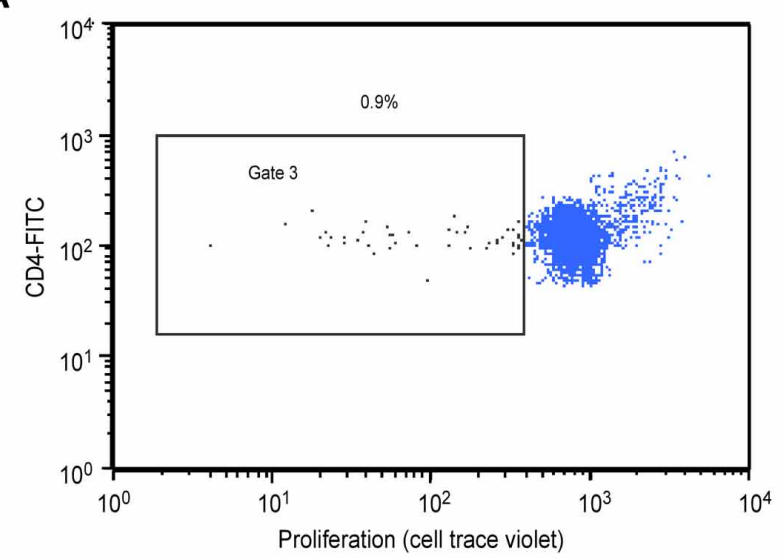

B

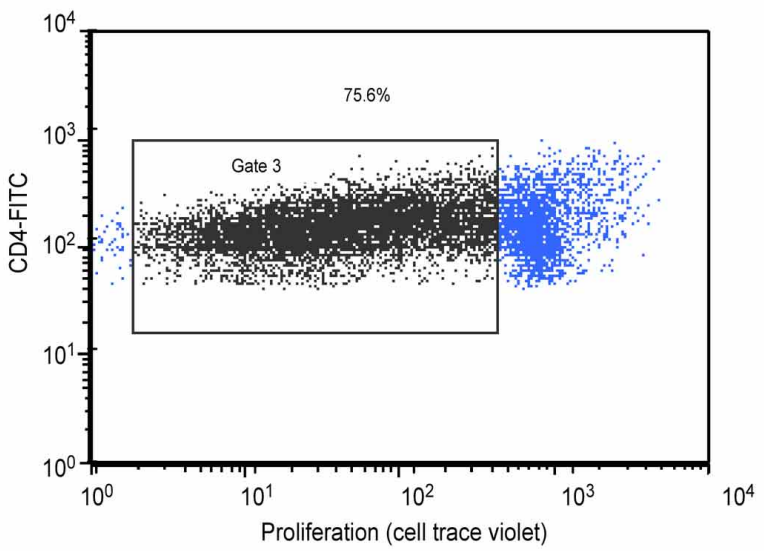

C
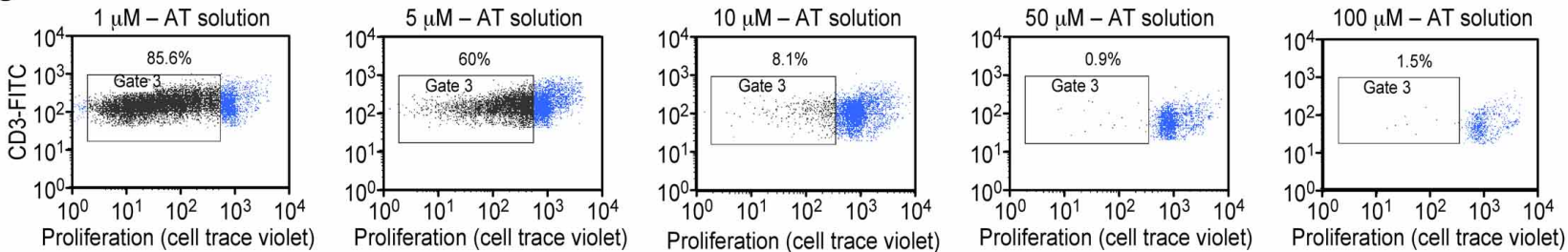

D
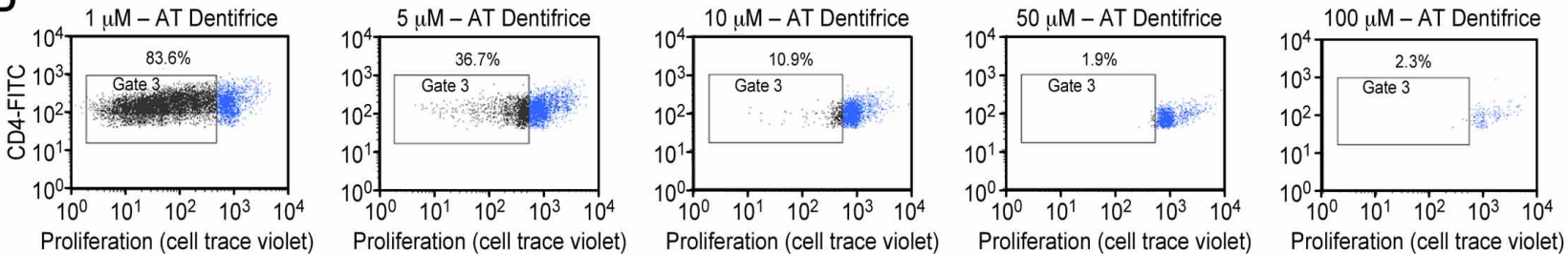

E
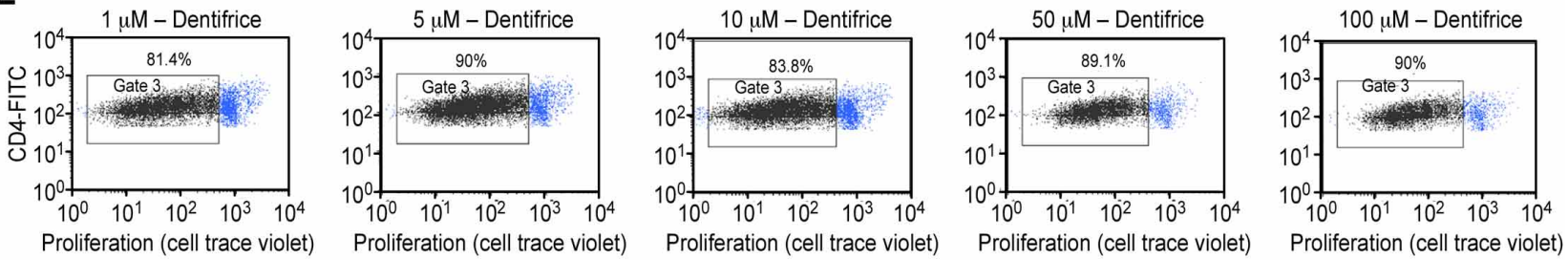

Fig. 2. Flow cytometry of PBMC cultures under the different conditions assessed. A. Gated CD4+ T cells and the proliferation that occurs as the CTV dye was diluted (gate) on samples not stimulated (basal) or stimulated with PHA ( $25 \mu \mathrm{g} / \mathrm{ml})$ after 4 days. B. CD4+ T cell proliferation under different concentrations of atorvastatin solution. C. CD4+T cell proliferation after exposure of different concentrations of dentifrice with atorvastatin. D. CD4+ T cell proliferation obtained under different concentrations of dentifrice without atorvastatin. 
proliferation; then, we compared the slopes for the proliferation variables between the different conditions, as we described in the Methods. We found no differences between the slopes for the atorvastatin solution group and the dentifrice with atorvastatin group (interaction $\mathrm{p}$-value $=$ 0.992), demonstrating that atorvastatin does not lose its immunosuppressive capacity when used in a dentifrice. However, there were differences between the slopes for atorvastatin solution and dentifrice without atorvastatin and between slopes for dentifrice with atorvastatin and dentifrice without atorvastatin (interaction p-value for both <0.0001), demonstrating that atorvastatin contained in a dentifrice dramatically inhibits CD4+ T cell proliferation and this effect is not associated to dentifrice without atorvastatin (Table I).

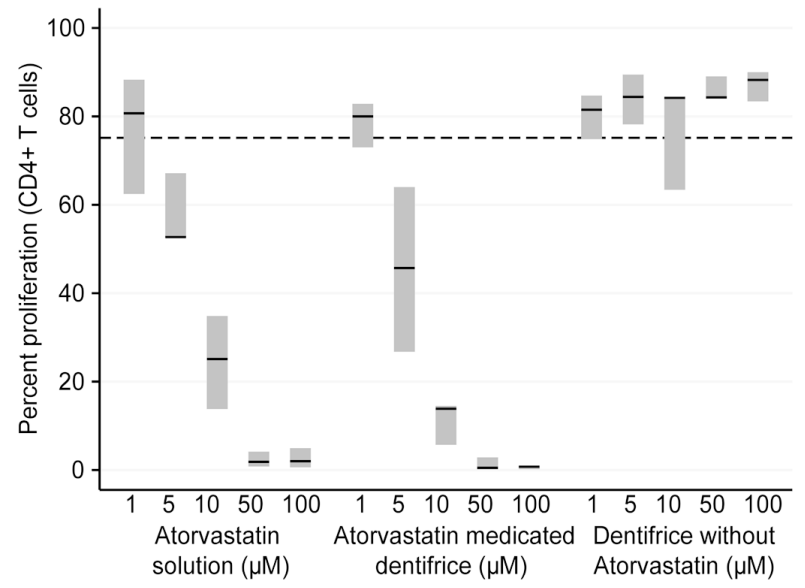

Fig. 3. Box plots of proliferation (\% CD4+ T cells) by concentration and exposure group.
Atorvastatin-medicated dentifrice does not affect cell viability. To evaluate the effect of an atorvastatin-medicated dentifrice on PBMC viability, we used PI to measure the percentage of dead cells in the different cultures under each condition assessed. We did not observe an increase in the percentage of dead cells (PI+ cells) after atorvastatinmedicated dentifrice exposure. These data indicate that the use of atorvastatin-medicated dentifrice does not affect cell viability. Slight increases in the percentage of dead cells were observed at the highest concentration of atorvastatin solution $(100 \mu \mathrm{M})$ (Fig. 4). Moreover, the variability slopes between atorvastatin-medicated dentifrice and dentifrice without atorvastatin were not statistically different ( $\mathrm{p}$-value $=0.634$ ), as shown in Table II.

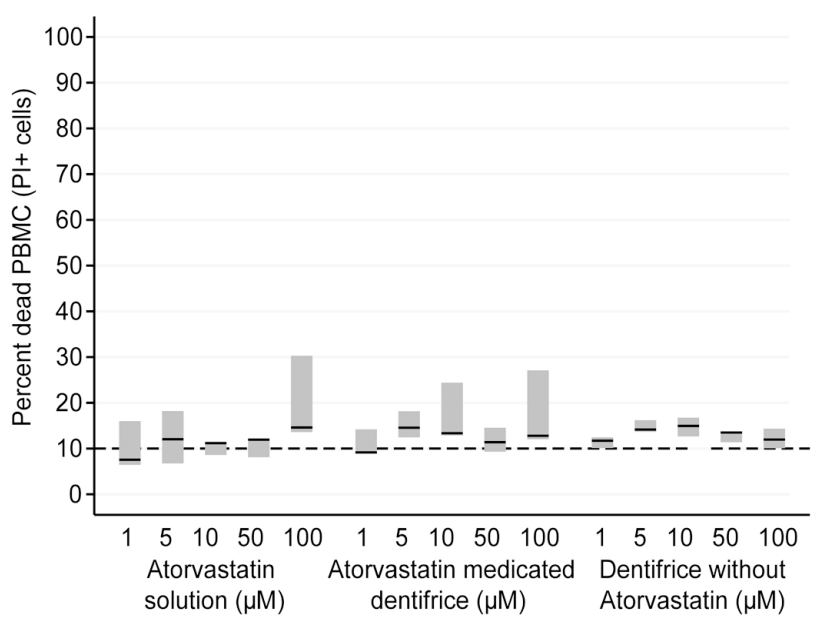

Fig. 4. Box plots of percentage of dead cells (PI+cells) by concentration and exposure group.

Table I. Proliferation percentage of CD4+ T cells after exposure to various concentrations.

\begin{tabular}{lcllcc}
\hline Exposure n=3 & Concentration & Median & QR & Minimum & Maximum \\
\hline Control (no exposure) & ------ & 75.16 & 10.31 & 67.22 & 77.53 \\
Atorvastatin solution & $1 \mu \mathrm{M}$ & 80.7 & 25.85 & 62.45 & 88.3 \\
& $5 \mu \mathrm{M}$ & 52.7 & 14.55 & 52.6 & 67.15 \\
& $10 \mu \mathrm{M}$ & 25.1 & 21.05 & 13.8 & 34.85 \\
Atorvastatin-medicated & $50 \mu \mathrm{M}$ & 1.85 & 3.35 & 0.8 & 4.15 \\
& $100 \mu \mathrm{M}$ & 2 & 4.35 & 0.6 & 4.95 \\
& $1 \mu \mathrm{M}$ & 80 & 9.84 & 73 & 82.85 \\
& $5 \mu \mathrm{M}$ & 45.7 & 37.25 & 26.75 & 64 \\
Dentifrice without atorvastatin & $10 \mu \mathrm{M}$ & 13.85 & 8.8 & 5.7 & 14.5 \\
& $50 \mu \mathrm{M}$ & 0.5 & 2.7 & 0.15 & 2.85 \\
& $100 \mu \mathrm{M}$ & 0.75 & 0.8 & 0.2 & 1 \\
& $1 \mu \mathrm{M}$ & 81.5 & 9.85 & 74.85 & 84.7 \\
& $5 \mu \mathrm{M}$ & 84.4 & 11.25 & 78.2 & 89.45 \\
& $10 \mu \mathrm{M}$ & 84.2 & 21.05 & 63.4 & 84.45 \\
& $50 \mu \mathrm{M}$ & 84.3 & 5.05 & 84 & 89.05 \\
\hline
\end{tabular}


Table II. Percentage of dead PBMC after the different exposures to the different dilutions.

\begin{tabular}{lccccc}
\hline Exposure n=3 & Concentration & Median & QR & Minimum & Maximum \\
\hline Control (no exposure) & ---- & 9.97 & 0.81 & 9.63 & 10.44 \\
Atorvastatin solution & $1 \mu \mathrm{M}$ & 7.55 & 9.57 & 6.43 & 16 \\
& $5 \mu \mathrm{M}$ & 12.03 & 11.45 & 6.75 & 18.2 \\
& $10 \mu \mathrm{M}$ & 11.17 & 2.9 & 8.6 & 11.5 \\
& $50 \mu \mathrm{M}$ & 11.95 & 3.95 & 8.1 & 12.05 \\
Atorvastatin-medicated dentifrice & $100 \mu \mathrm{M}$ & 14.6 & 16.7 & 13.6 & 30.3 \\
& $1 \mu \mathrm{M}$ & 9.15 & 5.1 & 9.1 & 14.2 \\
& $5 \mu \mathrm{M}$ & 14.55 & 5.7 & 12.45 & 18.15 \\
& $10 \mu \mathrm{M}$ & 13.35 & 11.55 & 12.85 & 24.4 \\
Dentifrice without atorvastatin & $50 \mu \mathrm{M}$ & 11.39 & 5.25 & 9.3 & 14.55 \\
& $100 \mu \mathrm{M}$ & 12.8 & 15.06 & 12.04 & 27.1 \\
& $1 \mu \mathrm{M}$ & 11.7 & 2.34 & 10.11 & 12.45 \\
& $5 \mu \mathrm{M}$ & 14.15 & 2.55 & 13.65 & 16.2 \\
& $10 \mu \mathrm{M}$ & 14.95 & 4.1 & 12.65 & 16.75 \\
& $50 \mu \mathrm{M}$ & 13.5 & 2.16 & 11.38 & 13.54 \\
& $100 \mu \mathrm{M}$ & 11.97 & 4.27 & 10.08 & 14.35
\end{tabular}

\section{DISCUSSION}

This in vitro study is the first report to evaluate the effects of atorvastatin using a dentifrice as delivery vehicle on cell viability and $\mathrm{CD} 4+\mathrm{T}$ cell proliferation.

Our results revealed that there is a dose-dependent decrease in $\mathrm{CD} 4+\mathrm{T}$ cell proliferation in the cultures treated with atorvastatin-medicated dentifrice, with values that are very similar to those obtained with the atorvastatin solution. In addition was important to demonstrate that an atorvastatinmedicated dentifrice did not affect cell viability, an aspect that could be relevant for future clinical use as a local treatment for patients with periodontal disease.

Previous studies conducted more than a decade ago showed that statins have anti-proliferative effects in lymphocytes and other cell types (Cuthbert \& Lipsky, 1990; Chakrabarti \& Engleman, 1991). Chakrabarti \& Engleman, found that lovastatin (a type of statin) inhibits the proliferation induced by the anti-CD3 antibody immobilized on $\mathrm{T}$ cells derived from human peripheral blood without affecting cell viability. They attributed this effect to the inhibition of mevalonate production, an important factor for cell cycle progression (Chakrabarti \& Engleman).

Blank et al. (2007), found that human $\mathrm{T}$ cell proliferation and activation were inhibited by pre-incubating PBMCs with atorvastatin at concentrations between 0.2 to $20 \mu \mathrm{M}$. In the studies by Chakrabarti \& Engleman and Blank et al., the proliferative properties were almost completely restored after applying mevalonic acid.
The immunosuppressive effect of statins has even been compared to the effects of conventional immunosuppressive drugs. One study found that statins have a dose-dependent inhibitory effect on human $\mathrm{T}$ cell proliferation, with maximum inhibitory effects observed at $50 \mu \mathrm{M}$ with atorvastatin and lovastatin and at $100 \mu \mathrm{M}$ with simvastatin. Moreover, it is noteworthy that the degree of immunosuppression was similar to that observed with conventional immunosuppressants (Jameel et al., 2013). This inhibitory effect on $\mathrm{T}$ cells was observed at a similar concentration in our study.

A recent study evaluated other potential mechanisms underlying the effects of statins on T cells (Bennaceur et al., 2014). This study evaluated the effects of atorvastatin on the telomerase activity in CD4+ and CD8+ T cells. Telomerase is an enzyme that catalyzes the replication of telomeres, genome components that are located at the ends of chromosomes and related to the lifespans of cells. Atorvastatin increased the telomerase activity level 6-fold over the original level, with the highest activity at a $0.3 \mu \mathrm{M}$ atorvastatin concentration after 5 days. The population of $\mathrm{CD} 4+\mathrm{T}$ cells suffered a greater induction of telomerase activity from atorvastatin stimulation compared to $\mathrm{CD} 8+\mathrm{T}$ cells $(650 \%$ vs. $256 \%)$. In contrast to our study, this study observed an increase in $\mathrm{T}$ cell proliferation from mononuclear cells stimulated with atorvastatin at concentrations up to $0.3 \mu \mathrm{M}$, with a significant increase in cell number after 5 days. However, at concentrations of 2-5 $\mu \mathrm{M}$, atorvastatin inhibited $\mathrm{T}$ cell proliferation without 
inducing cell death, which is consistent with our results (Bennaceur et al.).

The inhibitory effect on $\mathrm{T}$ cell proliferation caused by statins is a desirable effect in diseases where an exacerbated immune response causes damage to the host, such as what occurs in periodontal disease.

Kwak et al., observed that statins directly inhibit MHC-II expression via IFN- $\gamma$ and would therefore repress $\mathrm{T}$ cell activation mediated by MHC-II (Kwak et al.). Additionally, they also found that atorvastatin had the greatest repressor effect on MHC-II among the evaluated statins. MHC-II is required for both antigen presentation and $\mathrm{T}$ cell activation via the $\mathrm{T}$ cell receptor (TCR), which in turn promotes different responses, such as the release of cytokines that promote $\mathrm{T}$ cell proliferation and activation, the activation of antigen-presenting cells (APCs), and $\beta$ cell antibody production (Kwak et al.). Additionally, Kuipers et al. (2005) investigated the mechanisms by which simvastatin reduces the expression of MHC-II molecules in various human cell types. They found that this effect was due to a disruption in the cholesterol-containing microdomains responsible for transporting and concentrating the MHC-II molecules on the cell surface. Furthermore, they demonstrated that statins reduce the cell surface expression of other immunoregulatory molecules, such as MHC-I, CD3, CD4, CD8, CD28, CD40, CD80, CD86, and CD54 (Kuipers et al.). Additionally, Gurevich et al. (2005) suggested that the decreased expression of MHC-II would reduce the number of Th1 cells, which secrete pro-inflammatory cytokines, such as IFN- $\gamma$ and tumor necrosis factor alpha (TNF- $\alpha$ ).

Another potential mechanism that may be involved in the decrease in $\mathrm{T}$ cell proliferation is the fact that statins affect lipid rafts and two proteins that belong to the GTPase family (Ras/Rho), essentials for TCR signaling; thus, statins may suppress $T$ cell activation and proliferation by regulating TCRs (Ghittoni et al., 2005).

Additionally, Weitz-Schmidt (2002) suggest that statins, such as lovastatin and mevastatin, may selectively block LFA-1, decreasing the adhesion of lymphocytes to intercellular adhesion molecule-1 (ICAM1) and thus affecting T-cell co-stimulation.

The various mechanisms described above potentially explain how statins affect CD4+ T cell proliferation based on their immunomodulatory properties.

Clinically, individuals who suffer psoriasis, a chronic inflammatory disease, may benefit from the immunomodulatory effects of statins (Weitz-Schmidt). This disease shares certain characteristics with atherosclerosis, which is usually treated with these drugs. Both diseases are mediated by Th1 cells and exhibit increases in activated T cells expressing Th1 cytokine patterns (Shirinsky \& Shirinsky, 2007). Shirinsky \& Shirinsky demonstrated that a $40-\mathrm{mg} /$ day simvastatin exposure regimen results in the clinical improvement in psoriatic lesions, resulting from LFA-1 inhibition and a reduction in proinflammatory cytokine production by Th1.

As previously mentioned, the immunological mechanisms underlying periodontal disease share certain features with chronic inflammatory diseases (Hajishengallis, 2014).

Thus, the effect of statins could also result in clinical improvements in patients with periodontal disease. A study from our group showed that use of dentifrice medicated with $2 \%$ of atorvastatin resulted in significant improvements in clinical parameters, such as the mean probing depth, the mean clinical attachment level, bleeding on probing, the gingival index and the periodontal inflamed surface area, in patients with periodontal disease compared to use of a placebo dentifrice (Rosenberg et al., 2015).

Clinical studies have reported a $37 \%$ reduction in the rate of tooth loss in patients with chronic periodontitis who received statin therapy for at least 1 year (Cunha-Cruz et al., 2006). In a double-blind controlled clinical trial, Fajardo et al. (2010) observed significant improvements in tooth mobility and the distance between the enamelcementum limit and the alveolar bone in patients with chronic periodontitis who were treated with $20 \mathrm{mg}$ of atorvastatin for 3 months together with mechanical periodontal therapy compared with the placebo. Additionally, Pradeep et al. (2013) found significant gains in the attachment level after 3, 6 and 9 months of follow-up in patients undergoing mechanical periodontal therapy in addition to a gel treatment containing $1.2 \%$ simvastatin compared with those who only received mechanical periodontal therapy. A similar study using a $1.2 \%$ atorvastatin gel in addition to scaling and root planning detected greater insertion improvements at 9 months (Pradeep et al., 2013).

Our results revealed similar inhibitory effects on $\mathrm{CD} 4+\mathrm{T}$ cell proliferation in cultures treated with an atorvastatin solution or atorvastatin-medicated dentifrice, indicating that the immunomodulatory effect produced by atorvastatin is not diminished or modified when it is incorporated within a dentifrice base, such as that used in this study. Furthermore, the fact that the dentifrice without atorvastatin did not alter CD4+ T cell proliferation, with 
very similar values to the control culture, supports the idea that the effects on CD4+ T cells are due to the presence of atorvastatin. Additionally, this finding also demonstrates that the dentifrice base used in this study does not alter CD4+ T cell proliferation, indicating that it is an appropriate vehicle for the delivery of this drug.

The relevance of our study is that it assessed for first time the immunomodulatory effect of an atorvastatinmedicated dentifrice, which could be applied topically in clinical practice, allowing its use in higher concentrations at the sites of interest without adverse effects, compared to systemic statin therapy, which has been evaluated in most in vitro studies on this topic.

It is also noteworthy that none of the experimental samples significantly affected PBMC viability, indicating that both atorvastatin and the dentifrice base used are nontoxic to PBMCs.

Additionally, the finding that the inhibitory effect of atorvastatin on CD4+ T cell proliferation is dose-dependent, which is consistent with other in vitro studies, indicates the need for additional studies to determine the optimal concentration of statins for generating the appropriate $\mathrm{T}$ cell response with desirable clinical results. Ideally, the $\mathrm{T}$ cell proliferation values obtained need to be analyzed together with clinical effects. It would also be interesting to assess the direct effect of an atorvastatin-medicated dentifrice on CD4+ $\mathrm{T}$ cells in affected periodontal tissue (i.e., the soft wall of the periodontal pocket) to further support the results reported in this study.

A limitation of our pilot in vitro study was the small sample size, nevertheless considering this is the first in vitro study where the effect of atorvastatin as a dentifrice on $\mathrm{T}$ cells is evaluated, these preliminary results are really interesting because in all samples it was observed that $\mathrm{T}$ cell proliferation is modified under different concentrations of this atorvastatin-medicated dentifrice. An appropriate sample size is essential for future studies to confirm our results and support future research in this field. It could be interesting to continue investigating the effect of this drug as a dentifrice in different $\mathrm{T}$ cell subpopulations and other targets in T cells, with the aim of furthering knowledge concerning the mechanisms underlying the positive clinical response from the topical use of statins

In case of confirming the immunomodulatory effects of statins using a dentifrice, a medium that is already widely used and incorporated in oral hygiene habits of the population, this may have a significant impact on current oral health research.

\section{CONCLUSIONS}

Our pilot study observed that there is a dosedependent decrease in CD4+ T cell proliferation in the cultures treated with atorvastatin-medicated dentifrice. Studies with an appropriate sample size are needed to confirm our results.

Further in vitro studies should be conducted to evaluate the effects of this drug in subpopulations of T cell with a key role in the pathogenesis of periodontal disease, such as Th1, Th2, T helper 17 (Th17) and regulatory T cells (Tregs). These researches would provide a better understanding of the mechanisms underlying the effects of statins on the immune response.

\section{ACKNOWLEDGMENTS}

This work was supported by grants from the Universidad de los Andes, Santiago de Chile, Chile: FAI-MEDINOGTO201459.

ROSENBERG, D. R.; KERNITSKY, J. R.; ANDRADE, C. X.; RAMIREZ, V. ; VIOLANT, D. \& NART, J. Pasta dental medicada con atorvastatina inhibe de forma significativa la proliferación de células T CD4+: Un estudio piloto in vitro. Int. J. Morphol., 35(2):394-402, 2017.

RESUMEN: La literatura indica que las estatinas (medicamentos para bajar el colesterol), además de reducir el colesterol, tienen un efecto inmunomodulador. Este efecto puede ser beneficioso para el tratamiento de varias enfermedades, incluyendo la enfermedad periodontal. El objetivo de este estudio es evaluar el efecto inmunomodulador de una pasta dental medicada con atorvastatina sobre la proliferación celular de linfocitos T CD4+. A partir de células mononucleares de sangre periférica de donantes sanos (PBMC), se realizaron ensayos de proliferación y viabilidad de linfocitos T CD4+ bajo las siguientes condiciones: control, solución de atorvastatina, dentífrico medicado con atorvastatina y dentífrico sin atorvastatina, en concentraciones 1, 5, 10, 50 and $100 \mu \mathrm{M}$. Se realizó el análisis estadístico utilizando el modelo Generalized Equation Estimation (GEE) a fin de analizar la concentración versus la proliferación y la concentración versus el porcentaje de muerte celular para cada uno de los grupos. El dentífrico medicado con atorvastatina (valor $\mathrm{p}<0,0001$ ) y solución de atorvastatina (valor $\mathrm{p}<0,0001$ ) inhibieron significativamente la proliferación de células T CD4 + de una manera dependiente de la dosis en comparación con el dentífrico sin atorvastatina y condiciones de control. Sólo la relación entre la atorvastatina solución y el porcentaje de células muertas fue significativa en comparación con las otras condiciones (vale-p 0,019). Los resultados revelaron 
que el dentífrico medicado con atorvastatina en concentraciones de 1 a $100 \mathrm{mM}$ tenía efectos inmunomoduladores, inhibiendo la proliferación de células T CD4 + sin afectar la viabilidad de PBMC. Los otros componentes del dentífrico no afectaron la proliferación de células T CD4 + o la viabilidad celular, indicando su utilidad como vehículo para conseguir los efectos deseados de atorvastatina en el tejido periodontal. Todavía se necesitan ensayos clínicos controlados para evaluar los efectos clínicos de un dentífrico medicado con atorvastatina sobre el periodonto.

PALABRAS CLAVE: Atorvastatina cálcica; Dentífricos. Células T.; Citometría de flujo.

\section{REFERENCES}

Blank, N.; Schiller, M.; Krienke, S.; Busse, F.; Schätz, B.; Ho, A. D.; Kalden, J. R. \& Lorenz, H. M. Atorvastatin inhibits T cell activation through 3hydroxy-3-methylglutaryl coenzyme A reductase without decreasing cholesterol synthesis. J. Immunol., 179(6):3613-21, 2007.

Bennaceur, K.; Atwill, M.; Al Zhrany, N.; Hoffmann, J.; Keavney, B.; Breault, D.; Richardson, G.; von Zglinicki, T.; Saretzki, G. \& Spyridopoulos, I. Atorvastatin induces T cell proliferation by a telomerase reverse transcriptase (TERT) mediated mechanism. Atherosclerosis, 236(2):312-20. 2014.

Cekici, A.; Kantarci, A.; Hasturk, H. \& Van Dyke, T. E. Inflammatory and immune pathways in the pathogenesis of periodontal disease. Periodontol. 2000, 64(1):57-80, 2014.

Chakrabarti, R. \& Engleman, E. G. Interrelationships between mevalonate metabolism and the mitogenic signaling pathway in $\mathrm{T}$ lymphocyte proliferation. J. Biol. Chem., 266(19):12216-22, 1991.

Cunha-Cruz, J.; Saver, B.; Maupome, G. \& Hujoel, P. P. Statin use and tooth loss in chronic periodontitis patients. J. Periodontol., 77(6):10616, 2006.

Cuthbert, J. A. \& Lipsky, P. E. Inhibition by 6-fluoromevalonate demonstrates that mevalonate or one of the mevalonate phosphates is necessary for lymphocyte proliferation. J. Biol. Chem., 265(30):18568$75,1990$.

Ebersole, J. L.; Dawson, D. R. 3rd; Morford, L. A.; Peyyala, R.; Miller, C. S. \& Gonzalez, O. A. Periodontal disease immunology: 'double indemnity' in protecting the host. Periodontol. 2000, 62(1):163-202, 2013.

Fajardo, M. E.; Rocha, M. L.; Sánchez-Marin, F. J. \& Espinosa-Chávez, E. J. Effect of atorvastatin on chronic periodontitis: a randomized pilot study. J. Clin. Periodontol., 37(11):1016-22, 2010.

Gemmell, E.; Yamazaki, K. \& Seymour, G. J. The role of T cells in periodontal disease: homeostasis and autoimmunity. Periodontol. 2000, 43(1):14-40, 2007.

Ghittoni, R.; Patrussi, L.; Pirozzi, K.; Pellegrini, M.; Lazzerini, P. E.; Capecchi, P. L.; Pasini, F. L. \& Baldari, C. T. Simvastatin inhibits Tcell activation by selectively impairing the function of Ras superfamily GTPases. FASEB J., 19(6):605-7, 2005.

Greenwood, J.; Steinman, L. \& Zamvil, S. S. Statin therapy and autoimmune disease: from protein prenylation to immunomodulation. Nat. Rev. Immunol., 6(5):358-70, 2006.

Gurevich, V. S.; Shovman, O.; Slutzky, L.; Meroni, P. L. \& Shoenfeld, Y. Statins and autoimmune diseases. Autoimmun. Rev., 4(3):123-9, 2005

Hajishengallis, G. Immunomicrobial pathogenesis of periodontitis: keystones, pathobionts, and host response. Trends Immunol., 35(1):3$11,2014$.

Jameel, A.; Ooi, K. G. J.; Jeffs, N. R.; Galatowicz, G., Lightman, S. L. \& Calder, V. L. Statin Modulation of Human T-Cell Proliferation, IL-1 and IL-17 Production, and IFN- T Cell Expression: Synergy with
Conventional Immunosuppressive Agents. Int. J. Inflamm., 2013:e434586, 2013.

Kuipers, H. F.; Biesta, P. J.; Groothuis, T. A.; Neefjes, J. J.; Mommaas, A. M. \& van den Elsen, P. J. Statins affect cell-surface expression of major histocompatibility complex class II molecules by disrupting cholesterolcontaining microdomains. Hum. Immunol., 66(6):653-65, 2005.

Kwak, B.; Mulhaupt, F.; Myit, S. \& Mach, F. Statins as a newly recognized type of immunomodulator. Nat. Med., 6(12):1399-402, 2000.

Lee, S. J.; Qin, H. \& Benveniste, E. N. The IFN-gamma-induced transcriptional program of the CIITA gene is inhibited by statins. Eur. J. Immunol., 38(8):2325-36, 2008.

Lindy, O.; Suomalainen, K.; Mäkelä, M. \& Lindy, S. Statin use is associated with fewer periodontal lesions: A retrospective study. B. M. C. Oral Health, 8:16, 2008.

Okui, T.; Aoki-Nonaka, Y.; Nakajima, T. \& Yamazaki, K. The role of distinct T cell subsets in periodontitis - Studies from humans and rodent models. Curr. Oral Health Rep., 1(2):114-23, 2014.

Pradeep, A. R. \& Thorat, M. S. Clinical effect of subgingivally delivered simvastatin in the treatment of patients with chronic periodontitis: a randomized clinical trial. J. Periodontol., 81(2):214-22, 2010.

Pradeep, A. R.; Kumari, M.; Rao, N. S.; Martande, S. S. \& Naik, S. B. Clinical efficacy of subgingivally delivered $1.2 \%$ atorvastatin in chronic periodontitis: a randomized controlled clinical trial. J. Periodontol., 84(7):871-9, 2013.

Rosenberg, D. R.; Andrade, C. X.; Chaparro, A. P.; Inostroza, C. M.; Ramirez, V.; Violant, D. \& Nart, J. Short-term effects of $2 \%$ atorvastatin dentifrice as an adjunct to periodontal therapy: a randomized doublemasked clinical trial. J. Periodontol., 86(5):623-30, 2015.

Shirinsky, I. V. \& Shirinsky, V. S. Efficacy of simvastatin in plaque psoriasis: A pilot study. J. Am. Acad. Dermatol., 57(3):529-31, 2007.

Wang, C. Y.; Liu, P. Y. \& Liao, J. K. Pleiotropic effects of statin therapy: molecular mechanisms and clinical results. Trends Mol. Med., 14(1):3744, 2008.

Weitz-Schmidt, G. Statins as anti-inflammatory agents. Trends Pharmacol. Sci., 23(10):482-6, 2002.

\section{Corresponding author: \\ Dr. David Rosenberg}

Department of Oral and Maxillofacial Surgery

Faculty of Dentistry

Universidad de los Andes

Monseñor Álvaro del Portillo12455

Las Condes, Santiago

CHILE

E-mail: drosenberg@uandes.cl

Received: 13-01-2016

Accepted: 01-03-2017 